Research Article

\title{
Fatigue Performance of Rubber Concrete in Hygrothermal Environment
}

\author{
Yushan Liu $\mathbb{D},^{1,2}$ Jianyong Pang $\left.\mathbb{D}\right)^{1,2}$ and Weijing Yao $\mathbb{D}^{1,2}$ \\ ${ }^{1}$ State Key Laboratory of Mining Response and Disaster Prevention and Control in Deep Coal Mines, \\ Anhui University of Science and Technology, Huainan, Anhui 232001, China \\ ${ }^{2}$ School of Civil Engineering and Architecture, Auhui University of Science and Technology, Huainan, Anhui 232001, China
}

Correspondence should be addressed to Jianyong Pang; pangjyong@163.com

Received 19 March 2021; Accepted 7 July 2021; Published 16 July 2021

Academic Editor: Shazim A. Memon

Copyright ( $\odot 2021$ Yushan Liu et al. This is an open access article distributed under the Creative Commons Attribution License, which permits unrestricted use, distribution, and reproduction in any medium, provided the original work is properly cited.

It is widely accepted that the rubber concrete $(\mathrm{RC})$ originating from waste is a promising material that can contribute to the conservation and rational use of natural resources and the protection of the environment. However, the fatigue performance in a hygrothermal environment is a major concern because little pertinent information is available in the relevant literature. In this study, a cyclic loading test was carried out on RC subjected to different wet-dry cycles at different temperatures. The loading strain, plastic strain, and elastic strain of the concrete were compared and analyzed. The results revealed that the loading strain and plastic strain of the RC were obvious after the 1st loading cycle. As the number of loading cycles increased, the stress-strain curve became denser and the RC exhibited good elasticity. As the wet-dry cycles increased, the average plastic strain in the 10th-60th loading cycle increased while the elastic strain decreased. After 28 wet-dry cycles, the average plastic strain at $60^{\circ} \mathrm{C}$ increased by $42.31 \%$ compared with $20^{\circ} \mathrm{C}$. In fact, as the temperature became higher, the plastic damage incurred by the RC became more severe. Finally, the damage variable was defined based on the elastic modulus and plastic strain to evaluate the fatigue performance of the $\mathrm{RC}$ in a hygrothermal environment. The findings of this study can provide a useful reference for RC applications.

\section{Introduction}

With the rapid development of the automobile industry and the rapid increase in automobile demand, tire rubber waste, which is toxic and hazardous, has increased, and the recycling and disposal of end-of-life tires are considered as "black pollution" [1-3]. Most waste tires are piled up in landfills without any particular treatment, which poses a risk to the wellbeing of the ecological environment and creates fire hazards $[4,5]$. With regard to the recycling of rubber tires and reduction of environmental pollution, studies have attempted to introduce processed rubber aggregates as elastic materials into concrete to prepare rubber concrete (RC) $[6,7]$. Notably, RC can not only make use of waste tires with high added value but also improve the ductility, toughness, wear resistance, and skid resistance of concrete. Moreover, RC exhibits excellent performance in vibration reduction and noise reduction [8-10]. Although the addition of rubber reduces the compressive strength of concrete, its plastic deformation ability and fatigue performance are significantly improved $[11,12]$.

Nowadays, RC is widely used in bridges, tunnels, railways, airport runways, nuclear structures, and so on $[7,12]$. These structures are subjected to fatigue loading over long time periods while in service, and the antifatigue performance of the structure plays a vital role in its effective use in engineering applications $[13,14]$. Therefore, many studies have investigated the mechanical properties and damage of RC under cyclic loading [15-21]. Pang et al. [18] found that the total strain, elastic strain, and plastic strain of $\mathrm{RC}$ are significantly higher compared with those of ordinary concrete in the process of cyclic loading, while the relative strain is extremely small, which indicates good ductility and stability. Lv et al. [20] investigated the effect of rubber particles on the fatigue performance of self-compacting lightweight rubber aggregate concrete. Their results revealed that the 
fatigue life and strain increased as the replacement of rubber particles increased. Pacheco-Torres et al. [21] investigated the suitability of using discarded waste tire rubber particles in concrete rigid road pavements and presented an optimal combination of the size and proportion of rubber particles that improves the performance of the material subjected to cyclic loading stresses, which makes the material suitable for use in the construction of rigid concrete pavements.

However, in practical applications, tunnels, railways, and bridges are often subjected to two main groups of actions: traffic loadings and hygrothermal actions [22-24]. Multiple studies indicate that the strength, durability, and fatigue performance of the material rapidly decline in a hygrothermal environment [24-28]. Morshed et al. [26] found out the hygrothermal environments are deleterious to the durability of the interfacial bonding between concrete and CFRP. Tuakta and Büyüköztürk [27] observed a significant degradation of the bond strength when exposed to prolonged moisture condition, which can be up to $70 \%$ when specimens are conditioned for 8 weeks. Tang et al. [28] concluded that the higher the temperature, the lower the cohesive strength of the surrounding rock supporting structure under hygrothermal environments. Additionally, in areas with high temperature and humidity, a considerable proportion of highways suffer fatigue damage soon after being put into use, and this phenomenon develops rapidly [29-31]. Hence, it is understood that the fatigue performance of concrete in a hot and humid environment is somewhat different from that under normal conditions. Thus, it is necessary to investigate the fatigue performance of $\mathrm{RC}$ in a hygrothermal environment.

The objective of this study was to investigate the fatigue performance of RC in a hygrothermal environment. To this end, a cyclic loading test was carried out on the RC after different wet-dry cycles at different temperatures. Moreover, to quantify the fatigue damage of RC under the coupled action of the hygrothermal environment and loading, the damage variable was defined based on the elastic modulus and plastic strain. This has important practical significance for the promotion of RC engineering applications, natural resource preservation, and environmental protection.

\section{Materials and Methods}

2.1. Raw Materials. The cement used in this study was Chinese standard Portland cement; the chemical composition is presented in Table 1. The coarse aggregate was crushed limestone with continuous grading, particle size of $5-15 \mathrm{~mm}$, and an apparent density of $2780 \mathrm{~kg} / \mathrm{m}^{3}$. The fine aggregate was river sand with a fineness modulus of 2.6. A high-performance water reducer (HPWR) with a waterreducing rate of $30 \%$ was employed to ensure fluidity and water retention. The rubber particles had a size of $0.85 \mathrm{~mm}$ and density of $1030 \mathrm{~kg} / \mathrm{m}^{3}$. Table 2 represents the technical indexes of rubber particle, used for preparing the concrete. The appearance and microstructure of the rubber particle are presented in Figure 1.
TABle 1: Chemical composition of cement.

\begin{tabular}{lccccccc}
\hline Composition & $\mathrm{SiO}_{2}$ & $\mathrm{Al}_{2} \mathrm{O}_{3}$ & $\mathrm{Fe}_{2} \mathrm{O}_{3}$ & $\mathrm{CaO}$ & $\mathrm{MgO}$ & $\mathrm{SO}_{3}$ & $\begin{array}{c}\text { Ignition } \\
\text { loss }\end{array}$ \\
\hline Content (\%) & 22.60 & 5.03 & 4.38 & 63.11 & 1.46 & 2.24 & 1.18 \\
\hline
\end{tabular}

2.2. Preparation of Specimens. The mix proportions of $\mathrm{RC}$ are presented in Table 3. The dimensions of the cylindrical specimens were $\Phi 50 \times 100 \mathrm{~mm}$.

The materials were measured using an electronic balance and mixed in a double-horizontal-shaft forced-type concrete mixer. First, preweighted aggregate and rubber were mixed for $1 \mathrm{~min}$; then, binder material was added and mixed for $1 \mathrm{~min}$. Subsequently, the already measured water and water reducer were poured into the properly mixed dry materials and stirred for $3 \mathrm{~min}$ to ensure a mix with uniform plastic consistency. The mold was filled in three layers and consolidated using a vibratory table. Additionally, the top surface was smoothed with a trowel. The specimens were subjected to the laboratory conditions of $20 \pm 2{ }^{\circ} \mathrm{C}$ and $70 \%$ relative humidity. After hardening, the specimens were released from the molds and were cured in a saturated $\mathrm{Ca}(\mathrm{OH})_{2}$ solution at $20 \pm 2^{\circ} \mathrm{C}$ for $90 \mathrm{~d}$.

2.3. Test and Characterization. To prevent the moisture content from affecting the result of wet-dry cycles, all specimens were placed in an oven at the temperature of $105 \pm 5^{\circ} \mathrm{C}$ for $24 \mathrm{~h}$ before testing. After cooling, the specimens were divided into two groups and placed into thermostatic water bath box at the temperatures of $20^{\circ} \mathrm{C}$ and $60^{\circ} \mathrm{C}$, respectively. In order to investigate the influence of hygrothermal environment on the fatigue performance of $\mathrm{RC}$ accurately, a wet-dry cycle test (soaking $16 \mathrm{~h}+$ drying $6 \mathrm{~h}+$ cooling $2 \mathrm{~h}$ ) was used in lab conditions to simulate the humid and hot environment. The number of wet-dry cycles was 7,14 , and 28, respectively. Subsequently, the treated specimens were preserved in sealed polyethylene bags until the day of testing. The details of the test process are illustrated in Figure 2.

Using the RDL-200 electronic creep machine, uniaxial compression and cyclic loading tests were carried out on the RC specimens subjected to different wet-dry cycles. The uniaxial compression test was carried out at a rate of $1 \mathrm{~mm} /$ min until the specimen failed, so as to obtain the compressive strength, which is denoted as $f_{c}$. In the cyclic loading test, a small preload of $500 \mathrm{~N}$ was applied to the specimen before the test to ensure that the specimen and test device were properly aligned and centred. The equal amplitude cyclic loading method was used; the upper load was $30 \mathrm{kN}$ and the lower unloading limit was $0 \mathrm{kN}$. The rate of loading and unloading was set to $30 \mathrm{kN} / \mathrm{min}$. One loading and unloading process was considered as one cycle, and 60 cycles were carried out in total. The residual compressive strength was obtained at the rate of $1 \mathrm{~mm} / \mathrm{min}$ after cyclic loading and is denoted as $f_{c}^{\prime}$. The cyclic loading path of the test is shown in Figure 3. 
TABLE 2: Technical indexes of rubber particle.

\begin{tabular}{lccccccc}
\hline $\begin{array}{l}\text { Moisture } \\
\text { content }(\%)\end{array}$ & $\begin{array}{c}\text { Ash content } \\
(\%)\end{array}$ & $\begin{array}{c}\text { Acetone } \\
\text { extract (\%) }\end{array}$ & $\begin{array}{c}\text { Metal content } \\
(\%)\end{array}$ & $\begin{array}{c}\text { Fiber content } \\
(\%)\end{array}$ & $\begin{array}{c}\text { Sieve residue } \\
\text { content (\%) }\end{array}$ & $\begin{array}{c}\text { Tensile strength } \\
(\mathrm{MPa})\end{array}$ & $\begin{array}{c}\text { Elongation at } \\
\text { break }(\%)\end{array}$ \\
\hline 0.62 & 8.75 & 5.12 & 0.02 & 0.00 & 0.014 & 16.8 & 564 \\
\hline
\end{tabular}

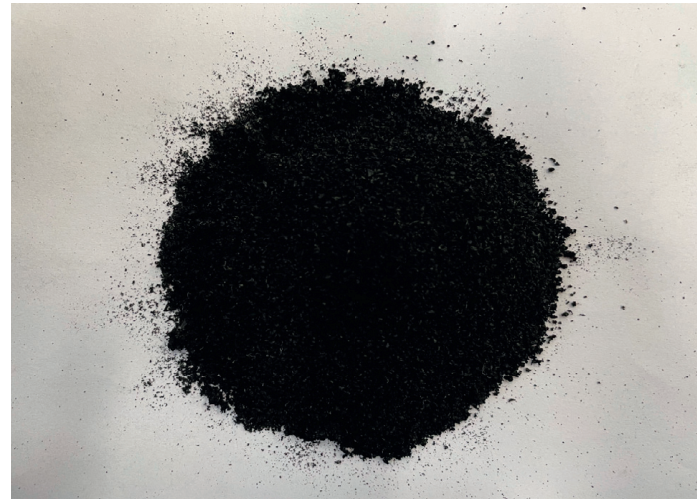

(a)

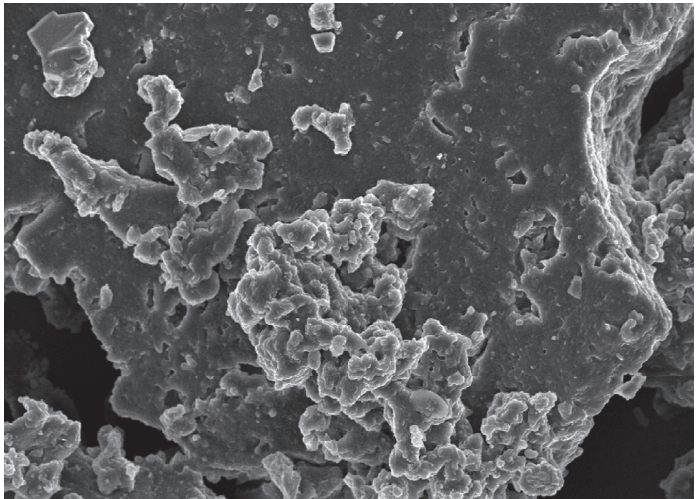

(b)

Figure 1: The (a) appearance and (b) microstructure of the rubber particles.

TABle 3: Mix proportions of $\mathrm{RC}\left(\mathrm{kg} / \mathrm{m}^{3}\right)$.

\begin{tabular}{lcccccc}
\hline Cement & Limestone & Sand & Rubber & Water & Water reducer & Water cement ratio \\
\hline 322 & 1225 & 689 & 275 & 161 & 3.21 & 0.5 \\
\hline
\end{tabular}

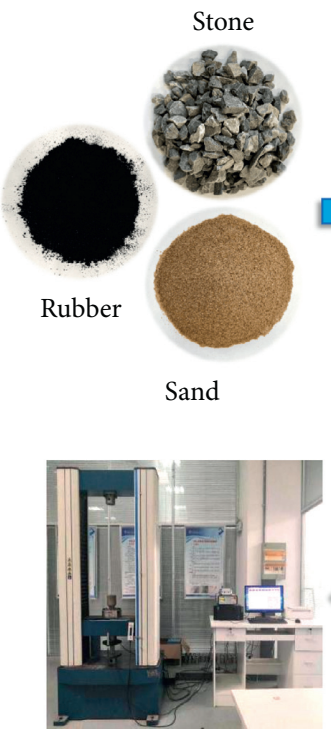

Cyclic loading

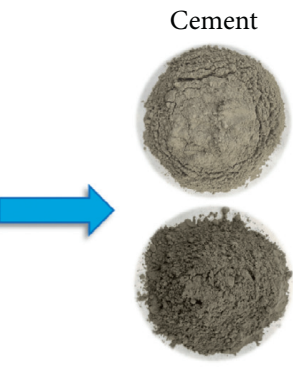

Fly ash

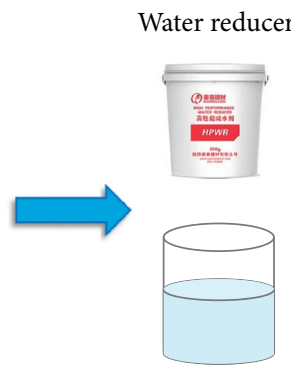

Water
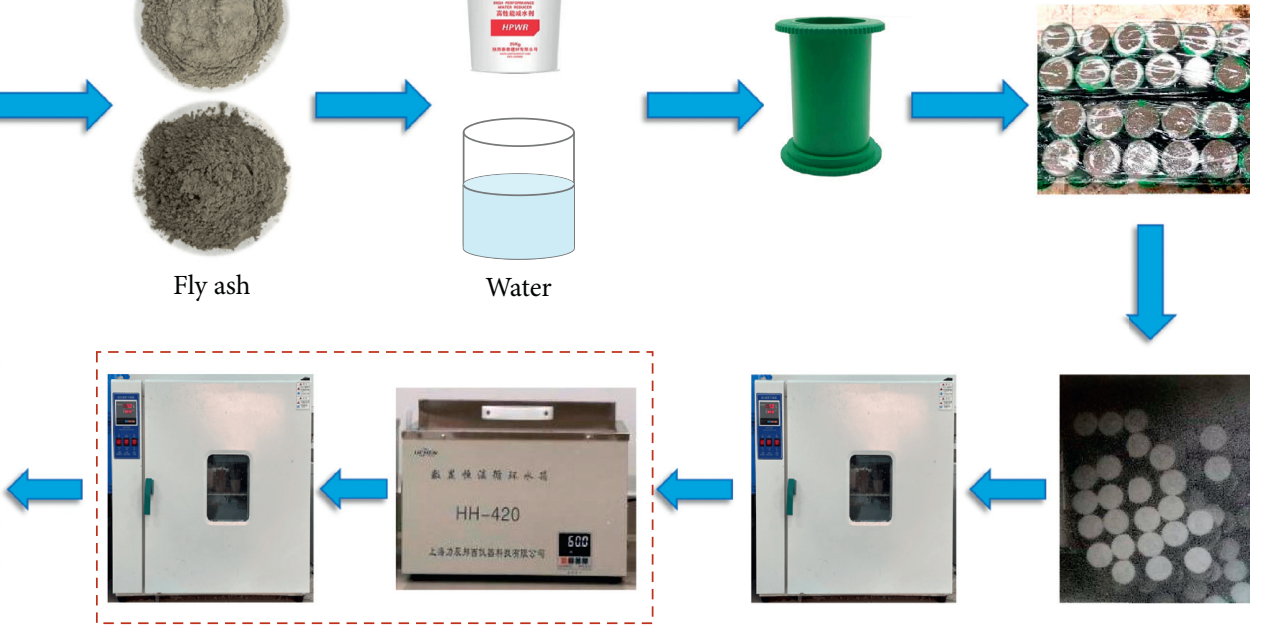

Wet-dry cycle

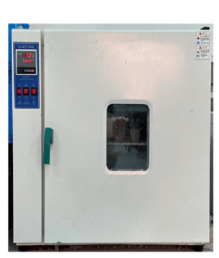

Dry treatment

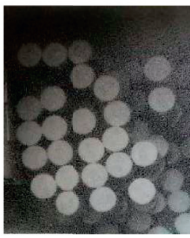

Curing for 90 days

Figure 2: Details of test process.

\section{Results and Discussion}

3.1. Compressive Strength Analysis. The influence of wet-dry cycles and cyclic loading on the compressive strength of $\mathrm{RC}$ is demonstrated in Figure 4. The compressive strength of RC decreases and the pace of decline is prone to be faster with increasing wet-dry cycles. When the temperature was $20^{\circ} \mathrm{C}$, the compressive strength of $\mathrm{RC}$ after $7,14,21$, and 28 wet-dry cycles decreased by $5.63 \%$, $16.90 \%, 30.99 \%$, and $38.03 \%$, while that of RC after cyclic loading declined by $10.28 \%, 23.00 \%, 37.87 \%$, and $45.99 \%$, respectively. After the same wet-dry cycles, the higher the temperature, the poorer the residual compressive strength. 


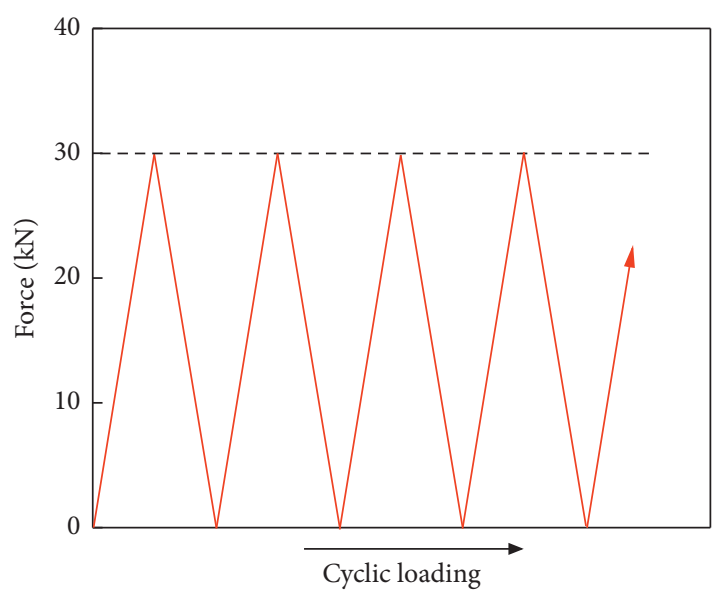

Figure 3: Cyclic loading path.

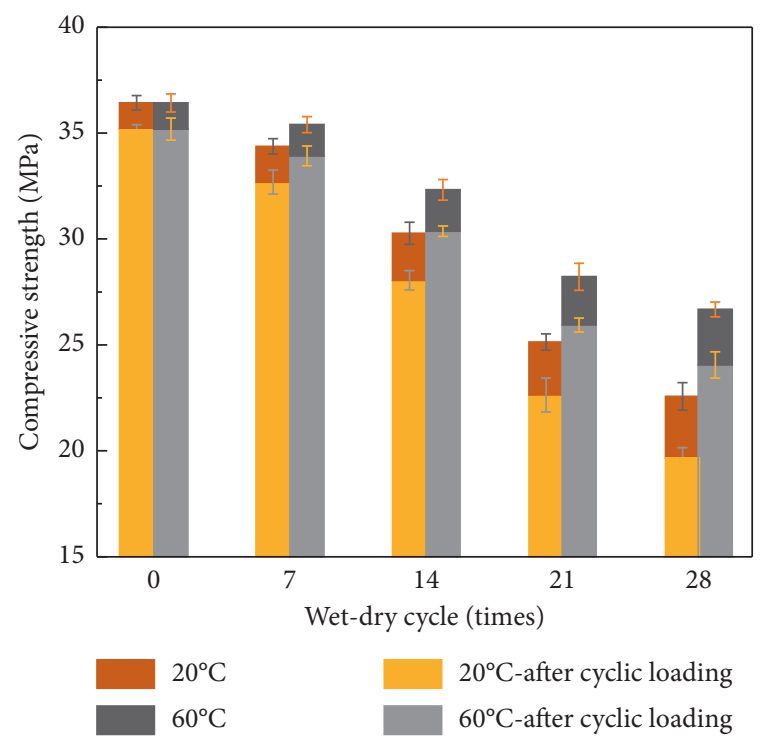

Figure 4: Compressive strength under different wet-dry cycles.

3.2. Typical Cyclic Loading Curves. The typical curve of RC under cyclic loading is shown in Figure 5(a). As can be seen, the stress-strain curve of RC is first sparse and then becomes dense. The deformation of RC under cyclic loading mainly occurs in the first cycle and is observed as a large opening at the bottom of the curve. The hydrophobicity of the rubber particles resulted in a weak interface between the rubber particles and the cement matrix, which led to many initial pores in the specimen. Once the specimen was loaded, the internal pores of RC were compressed and microcracks quickly appeared, mainly with plastic deformation. Because rubber particles have better elasticity and toughness, the addition of rubber particles into concrete is equivalent to the introduction of an elastomer to some extent [32,33]. Hence, the deformation of RC is mainly elastic deformation after the primary pores have been gradually compacted, which indicates that there exists a reduced hysteretic loop area and a denser curve.

As can be seen from the single-cycle curve in Figure 5(b), the loading period is mainly divided into three stages: the compaction stage, approximate elastic stage, and crack evolution stage [34]. In Figure 5(b), $\varepsilon_{l}$ represents the loading strain, $\varepsilon_{p}$ represents the plastic strain (also called plastic strain), and $\varepsilon_{e}$ represents the elastic strain during each loading-unloading cycle. The curve in the compaction stage is concave, which indicates that the stress is kept at a low value and grows very slowly as the strain increases. This stage corresponds to the process of compacting and closing the internal pores. As the pores are gradually compacted, the specimen is uniformly compressed and the stress-strain curve increases approximately linearly, which indicates the approximate elastic stage. As the load and strain increase, the stress slowly increases and the curve exhibits a convex shape, which indicates the stage of microcrack evolution. As the load continues to increase, the curve exhibits a convex shape and the strain continues to increase, which indicates the stage of crack evolution. This is attributed to the breaking of the internal pores as the load increases, and the generation and expansion of microcracks with the breaking of the pores. The brittleness of concrete was weakened while its ductility is enhanced, and ductile deformation becomes the main deformation type.

3.3. Loading Strain Analysis. The relationships between the loading strain and the number of loading cycles are shown in Figure 6. As can be seen, the variation trend of the loading strain of the RC specimen with the number of loading cycles is essentially the same, although the number of wet-dry cycles is different. The loading strain increased with the number of cyclic loading, and the loading strain rate in the 0th-10th loading was obvious. After 10 loading cycles, the strain slowly increased and the curve tended to be flat. When the number of wet-dry cycles of the RC at $20^{\circ} \mathrm{C}$ was $0,7,14$, 21 , and 28 , the loading strain in the 0 th-10th cycle accounted for $97.22 \%, 96.36 \%, 96.86 \%, 91.2 \%$, and $89.93 \%$ of the total strain, respectively.

Additionally, the loading strain increased with the wetdry cycles under the same number of loading cycles. At $20^{\circ} \mathrm{C}$, compared with the RC specimens without soaking, the loading strain in the 0th-10th loading cycle of the specimens, which had been subjected to $7,14,21$, and 28 wet-dry cycles, increased by $7.14 \%, 17.62 \%, 25.95 \%$, and $46.67 \%$, respectively, and the loading strain in the 0th-60th loading cycle increased by $8.10 \%, 18.06 \%, 34.26 \%$, and $58.56 \%$. The influence of the wet-dry cycles on the loading strain was more significant as the number of loading cycles increased.

3.4. Plastic Strain Analysis. Figure 7 presents the average plastic strain within the 10th-60th loading cycle under different wet-dry cycles. As can be seen, the average plastic strain increased with the wet-dry cycles. When the temperature was $20^{\circ} \mathrm{C}$, compared with the untreated $\mathrm{RC}$ specimens, the average plastic strain increased by $31.82 \%$ after 7 wet-dry cycles. As the wet-dry cycles increased, the average plastic strain increased by $40.91 \%, 77.27 \%$, and $254.55 \%$.

When the number of wet-dry cycles was the same, the average plastic strain at $60^{\circ} \mathrm{C}$ was larger compared with that 


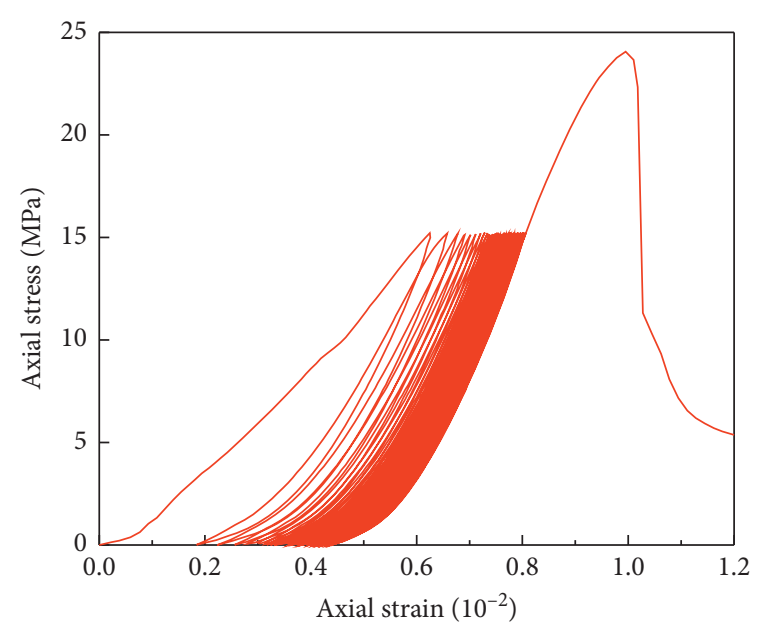

(a)

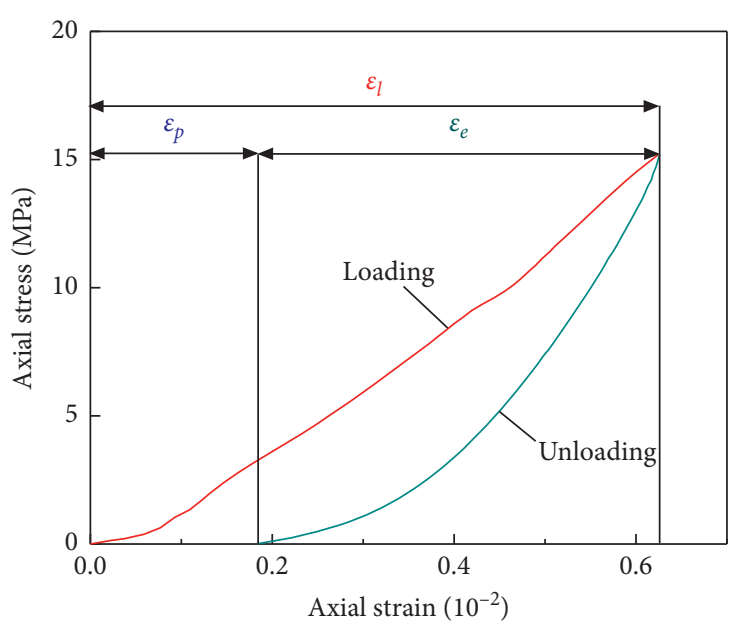

(b)

FIgURE 5: Typical RC curves under cyclic loading: (a) full strain curve under cyclic loading; (b) single-cycle curve.

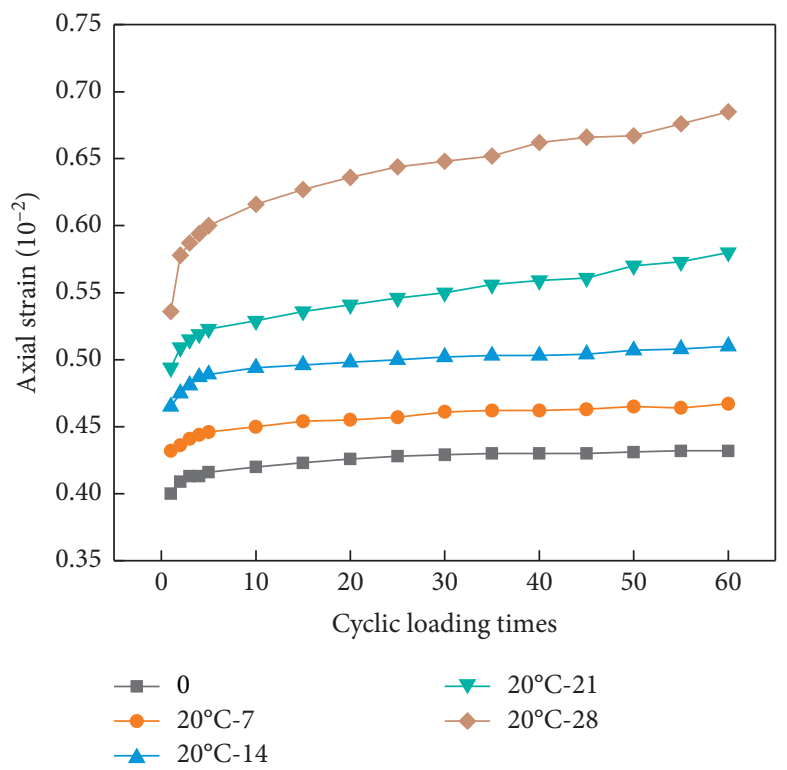

(a)

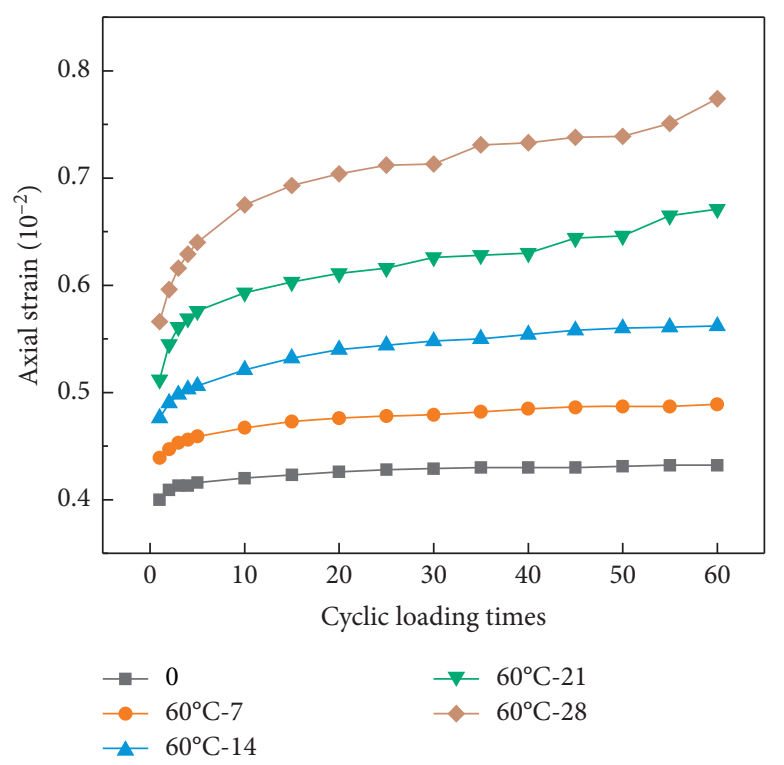

(b)

FIGURE 6: Relationships between loading strain and number of loading cycles: (a) $20^{\circ} \mathrm{C}$; (b) $60^{\circ} \mathrm{C}$.

at $20^{\circ} \mathrm{C}$. This suggests the growth rate of the irreversible plastic strain was greater under higher temperature. Because rubber particles have good elasticity, the plastic deformation was mainly caused by the pores and cracks in the cement matrix. In a humid and hot environment, high temperature accelerates the wet-dry erosion, which further weakens the bonding of the rubber particles and cement matrix. Therefore, under cyclic loading, the accumulation of plastic deformation occurs owing to the internal crack propagation and damage evolution.

3.5. Elastic Strain Analysis. The deformation of concrete under loading, which can be recovered after unloading, is called elastic deformation. The difference between the loading strain $\varepsilon_{1}$ at the maximum axial stress of $30 \mathrm{kN}$ and the plastic strain $\varepsilon_{p}$ when the specimen is unloaded to $0 \mathrm{kN}$ is defined as the elastic strain $\varepsilon_{e}$. The average elastic strain within the 10th-60th loading cycle under different wet-dry cycles is shown in Figure 8.

It can be deduced from Figure 8 that the average elastic strain shows a fluctuating reduction. Obviously, the average elastic strain after the first seven wet-dry cycles is dropped at most, which is up to $3.79 \%$ at $20^{\circ} \mathrm{C}$, and $5.96 \%$ at $60^{\circ} \mathrm{C}$. As wet-dry cycles increased, the pace of the decline tended to be slow. It is attributed to the fact that the deterioration of RC is a continuing process induced by the wet-dry cycles. During the initial wet-dry cycles, the rearrangement of aggregates and cement matrix promotes the development of crack quickly. 


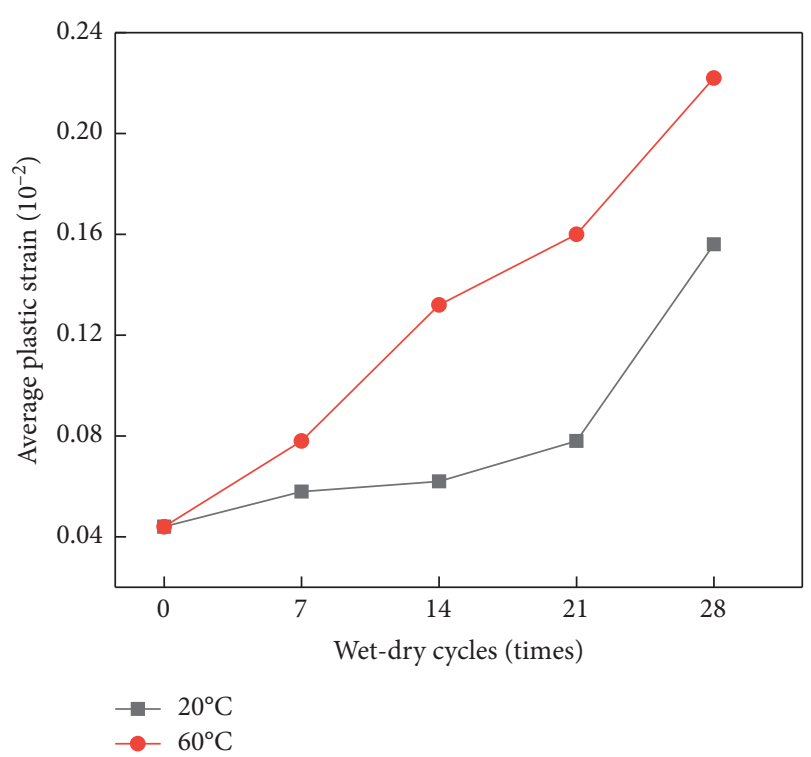

FIgURe 7: Average plastic strain in 10th-60th loading cycle under different wet-dry cycles.

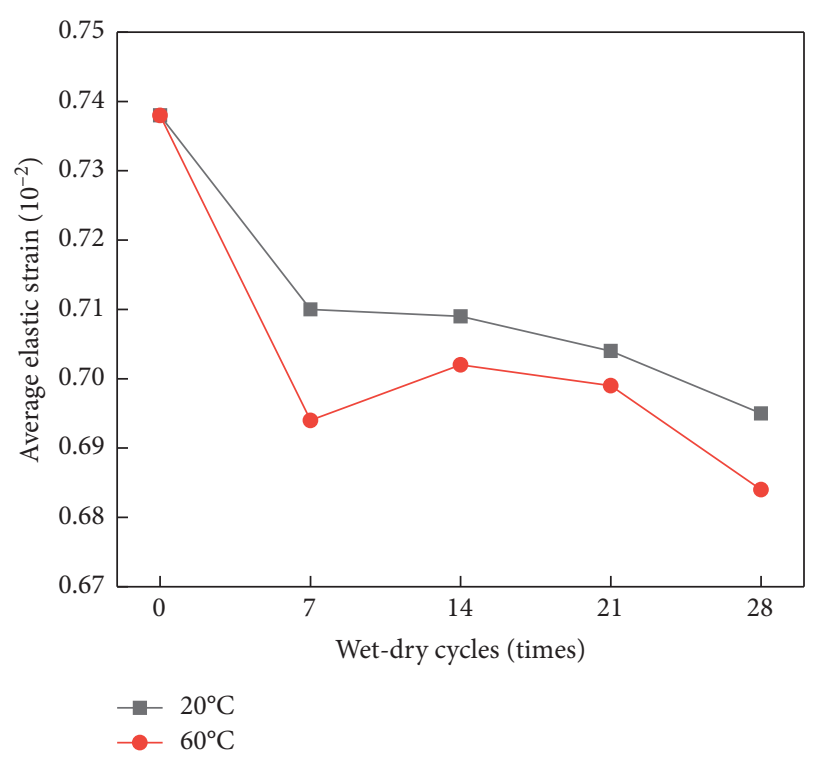

FIGURE 8: Average elastic strain in 10th-60th loading cycle under different wet-dry cycles.

As can be seen, the average elastic strains at $20^{\circ} \mathrm{C}$ were higher than those at $60^{\circ} \mathrm{C}$, which confirms that the coupled corrosion of the hygrothermal environment and loading makes the process of durability performance deterioration easier, resulting in partial elastic strain transformed into plastic strain.

3.6. Damage Evolution. Damage refers to the microdefects or microcracks that exist inside the material as a result of manufacturing or external factors and results in the attenuation of mechanical properties and increase of deformation $[35,36]$. A damage variable is a reference physical quantity, such as the stress, strain, elastic modulus, density, and energy density, and can be used to describe the internal damage of the material [37]. The damage variable can be selected according to the research object.

3.6.1. Damage Variable of Elastic Modulus. The elastic modulus $E_{0}$ reflects the deformation resistance of concrete and is essential for evaluating the material performance. The elastic modulus $E_{0}$ is calculated using the elastic stage of the unloading curve, which can be expressed as follows:

$$
E_{0}=\frac{\sigma}{\varepsilon_{e}} .
$$

The elastic modulus $E_{0}$ of the RC subjected to various wet-dry cycles after 10,20,30,40,50, and 60 loading cycles is shown in Figure 9. As can be seen, $E_{0}$ of the RC specimen after 10, 20,30, 40, 50, and 60 loading cycles fluctuated within a certain range. Therefore, the average $\bar{E}_{0}$ value was used to investigate the influence of the wet-dry cycles on the elastic modulus of RC [38]. According to Ma et al. [39], the increase of $\bar{E}_{0}$ after different wet-dry cycles was defined as the total damage variable $D_{E n}$, and the average increase of $\bar{E}_{0}$ after each adjacent wet-dry cycle was defined the phase damage variable $\Delta D_{E}$, as follows:

$$
\begin{gathered}
D_{E n}=\frac{\bar{E}_{0 n}-\bar{E}_{00}}{\bar{E}_{00}}, \\
\Delta D_{E}=\frac{D_{E n}-D_{E m}}{n-m},
\end{gathered}
$$

where $\bar{E}_{00}$ is the average elastic modulus of RC without soaking and $\bar{E}_{0 n}$ is the average elastic modulus of RC when the wet-dry cycle is $n$. When the number of the wet-dry cycle $n$ is $7,14,21$, and 28 , the corresponding $m$ value is $0,7,14$, and 21 .

According to the definition in (2) and (3), the trend of the total damage variable $D_{E n}$ and the phase damage variable $\Delta D_{E}$ of the RC specimen subjected to various wet-dry cycles are shown in Figure 8.

As shown in Figures 9 and 10, as the wet-dry cycles increased, the elastic modulus increased, and its total deterioration gradually increased. This is attributed to the fact that the amount of damage and energy dissipation increased, which accelerated the fatigue process. When the temperature was $20^{\circ} \mathrm{C}$, the total damage variable of RC was $16.28 \%$ after seven wet-dry cycles. As the wet-dry cycles increased, the total degradation variables were $19.73 \%, 21.18 \%$, and $22.60 \%$.

However, during this process, the phase deterioration gradually decreased: the $0-7$ phase of damage decreased up to $2.33 \%$, and the $21-28$ phase of damage decreased by the minimum amount of only $1.41 \%$, which indicates that the wet-dry cycles result in the gradual deterioration of RC.

3.6.2. Damage Variable of Plastic Strain. Considering that the concrete is brittle and ductile, and its failure is mainly caused by excessive deformation, strain is one of the important indices for controlling the structural deformation 


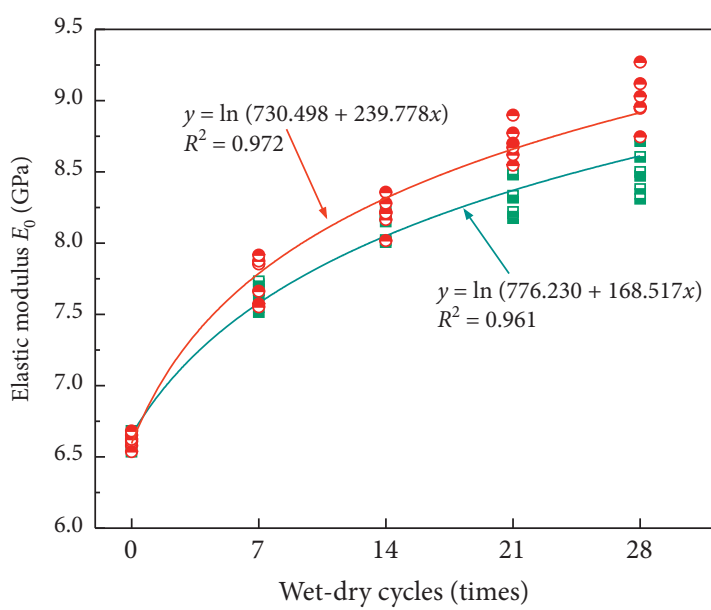

$$
\begin{aligned}
& \text { - } 20^{\circ} \mathrm{C} \text {-experimental data } \quad 20^{\circ} \mathrm{C} \text {-fitting curve } \\
& \text { - } 60^{\circ} \mathrm{C} \text {-experimental data } \quad 60^{\circ} \mathrm{C} \text {-fitting curve }
\end{aligned}
$$

FIGURE 9: Elastic modulus of RC after being subjected to different wet-dry cycles.

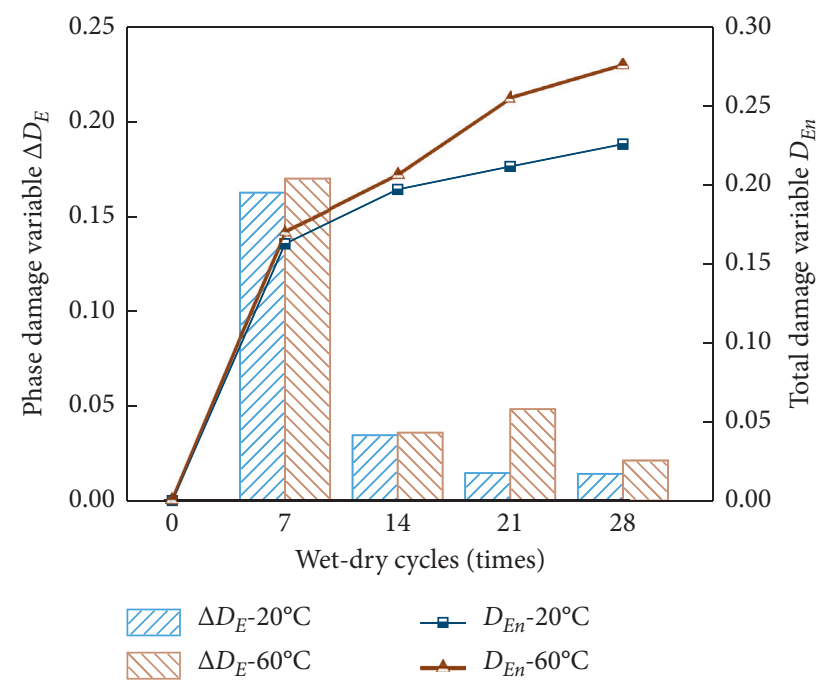

Figure 10: Total damage variable and phase damage variable of RC after being subjected to different wet-dry cycles.

and investigating the safety of concrete. The failure strain, which is also known as peak strain, is the strain that indicates structural failure and is denoted as $\varepsilon_{f}$. The plastic strain $\varepsilon_{p}$ refers to the deformation that cannot be recovered, which is known as residual deformation. To measure the fatigue plastic damage of RC specimens under cyclic loading, the ratio of the plastic strain $\varepsilon_{p}$ to the peak strain $\varepsilon_{f}$ in $0-60$ loading cycles is defined as the damage variable $D_{\varepsilon}$ and is expressed as follows [19]:

$$
D_{\varepsilon}=\frac{\varepsilon_{p}}{\varepsilon_{f}}
$$

Figure 11 shows the variation of $D_{\varepsilon}$ under different wetdry cycles. Under the coupling action of wet-dry cycles and cyclic loading, the damage variable of the RC specimen increased with the number of wet-dry cycles. When the

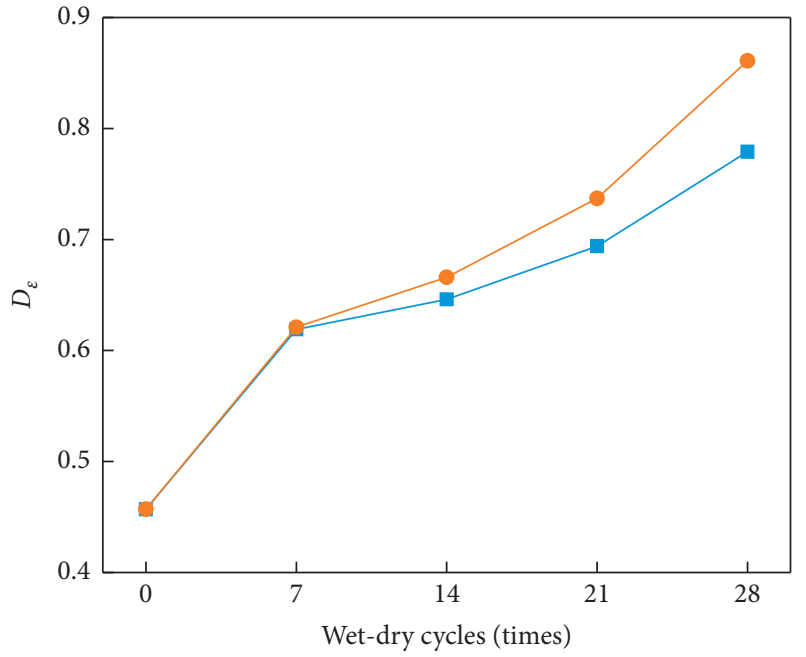

$-20^{\circ} \mathrm{C}$
$-60^{\circ} \mathrm{C}$

FIgURE 11: Damage variable $D_{\varepsilon}$ of RC subjected to different wet-dry cycles.

temperature was $20^{\circ} \mathrm{C}$, the $D_{\varepsilon}$ values of RC after $0,7,14,21$, and 28 wet-dry cycles were $0.457,0.617,0.626,0.651$, and 0.679 , respectively. Comparing the specimen without wetdry cycle, the $D_{\varepsilon}$ values of RC at $20^{\circ} \mathrm{C}$ after $7,14,21$, and 28 wet-dry cycles increased by $35.01 \%, 36.98 \%, 42.45 \%$, and $48.58 \%$, while those of $60^{\circ} \mathrm{C}$ increased by $35.89 \%, 45.73 \%$, $61.27 \%$, and $88.40 \%$, respectively. After the same wet-dry cycles, the $D_{\varepsilon}$ values increased with the temperature. After 7 , 14,21 , and 28 wet-dry cycles, compared with $20^{\circ} \mathrm{C}$, the $D_{\varepsilon}$ value increased by $0.32 \%, 3.19 \%, 6.61 \%$, and $11.76 \%$, respectively.

3.6.3. Damage Mechanism Analysis. From the results we have obtained, one can conclude that the damage caused by the wet-dry cycles to the concrete is not negligible. Figure 12 shows the schematic diagram of internal structure, and Figure 13 displays the microstructure of the interfacial zone in the hygrothermal environment. The repeated soaking and high temperature drying precipitated the internal microcracks through. The soluble particles in the specimen were lost through the leftover pores, while the remaining particles expanded during the drying process and formed new internal voids and cracks. With the increase of wet-dry cycles, the pores left by the loss of soluble components accumulate (Figures 13(g) and 13(h)). Under repeated loading, the slip distance between the particles increased, and the cracks had sufficient time to develop and expand, which led to a loose internal structure and increased deformation. After 21 wetdry cycles, wider fractures can be observed at the interface zone compared to the microstructure without wet-dry cycles (Figures 13(e) and 13(f)), illustrating the fact that the formation of fractures and pores significantly aggravates the deformation.

Comparing the specimens subjected to the same wet-dry cycles, it can be seen that the higher the temperature, the 


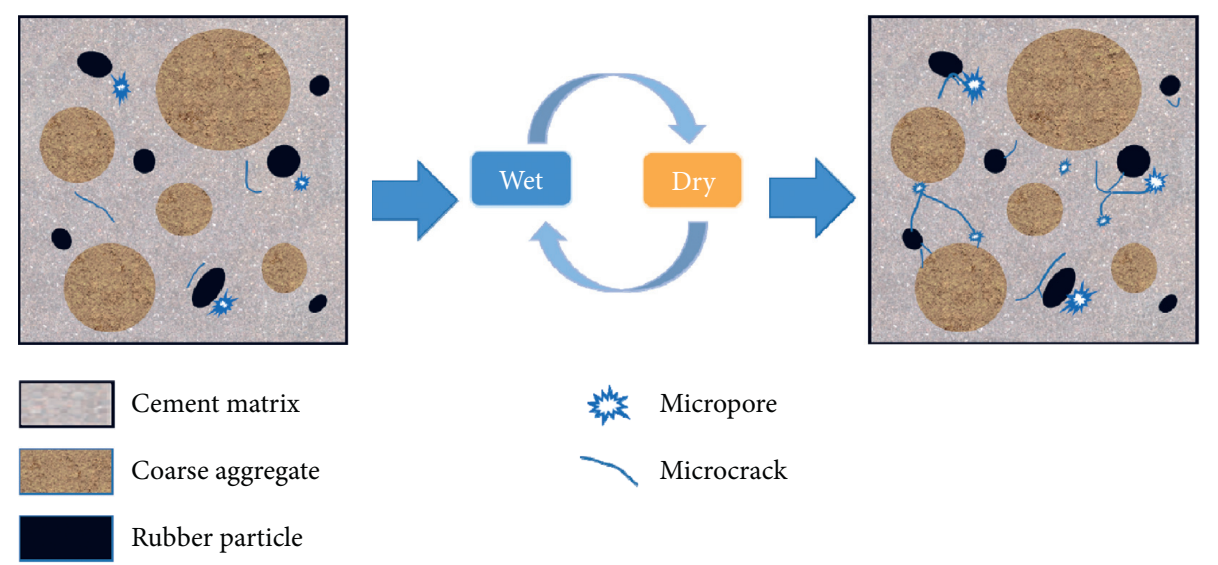

FIGURE 12: The internal structure schematic diagram of RC subjected to different wet-dry cycles.

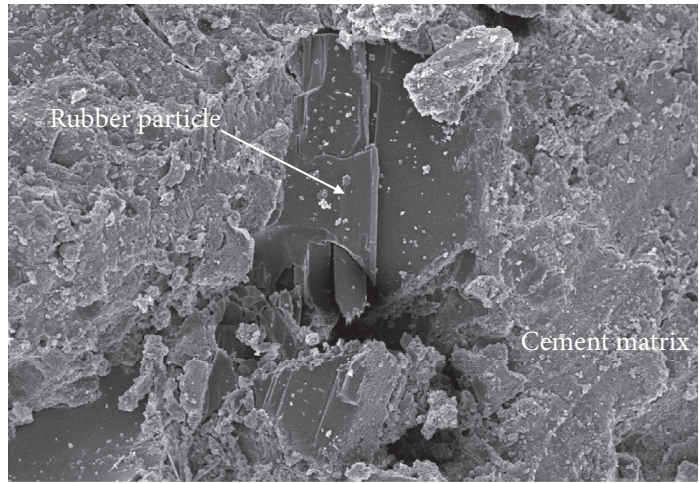

(a)

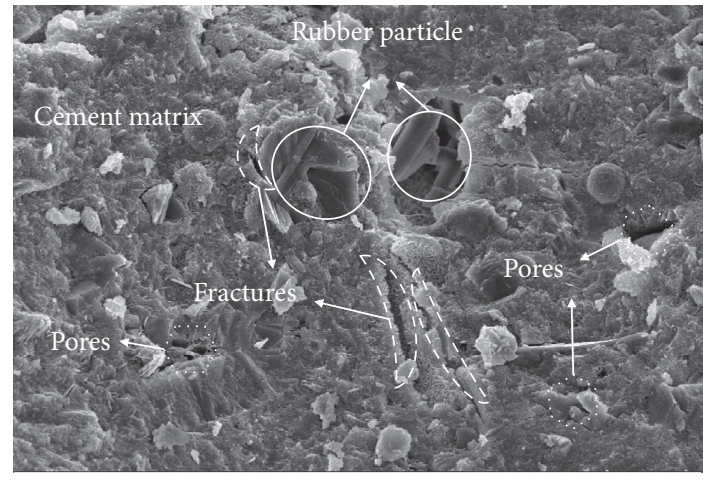

(c)

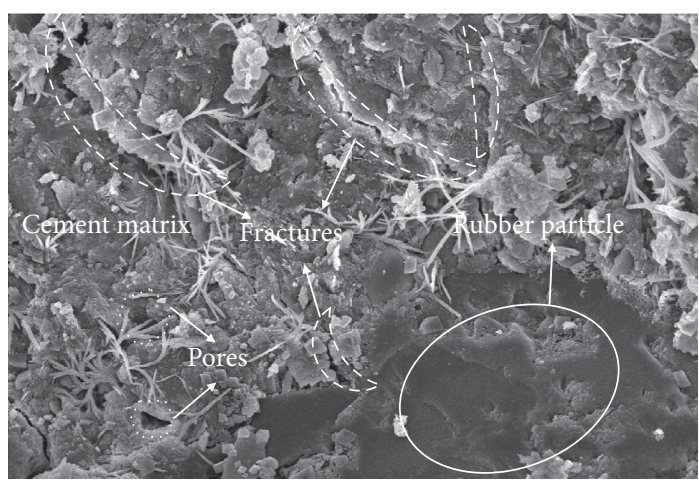

(e)

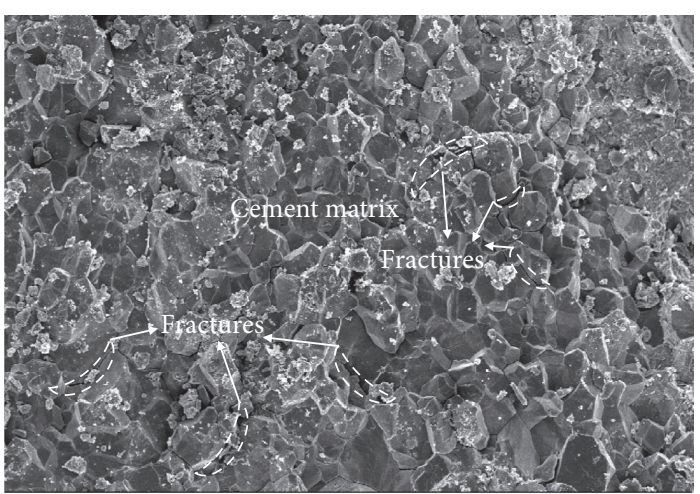

(b)

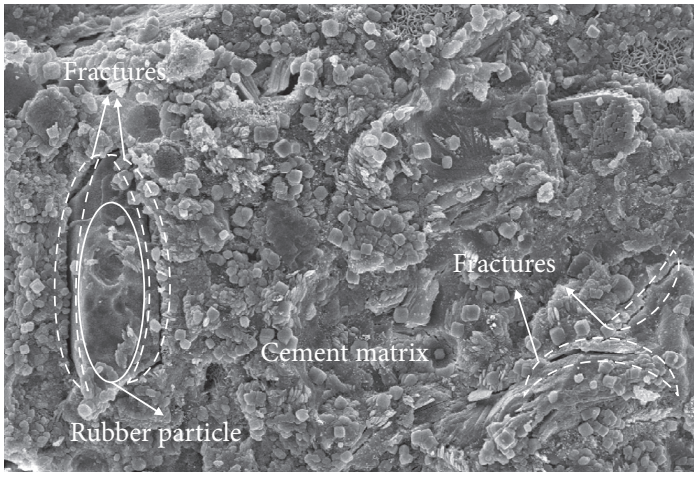

(d)

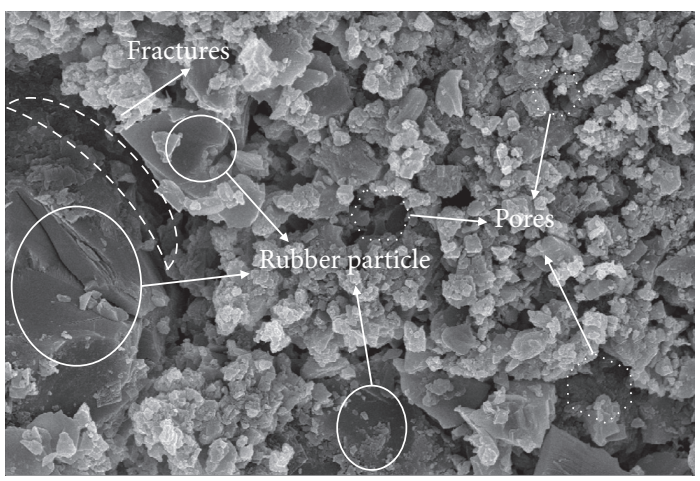

(f)

FIGURE 13: Continued. 


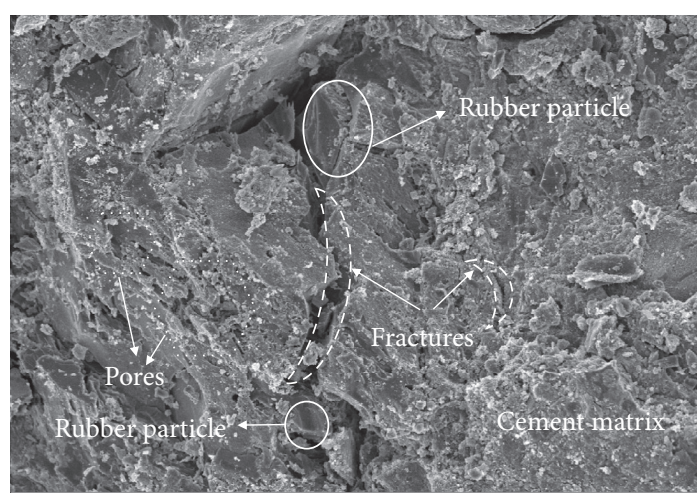

(g)

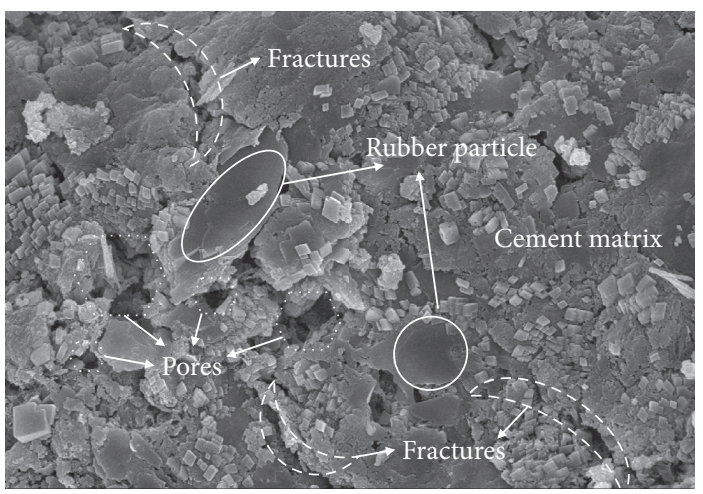

(h)

FIGURE 13: Microstructures of the interfacial transition zone, subjected to (a) 0 wet-dry cycles, (b) 0 wet-dry cycles, (c) 14 wet-dry cycles at $20^{\circ} \mathrm{C}$, (d) 14 wet-dry cycles at $60^{\circ} \mathrm{C}$, (e) 21 wet-dry cycles at $20^{\circ} \mathrm{C}$, (f) 21 wet-dry cycles at $60^{\circ} \mathrm{C}$, (g) 28 wet-dry cycles at $20^{\circ} \mathrm{C}$, and (h) 28 wetdry cycles at $60^{\circ} \mathrm{C}$.

looser the cement matrix and the longer the fracture length. The interaction effect caused by the negative influence of the temperature and wet-dry cycles resulted in the differential deformation and internal stress of the rubber particles and cement paste, and the internal structure was not as dense as before. This resulted in the more severe fatigue plastic damage of RC in the hygrothermal environment.

\section{Conclusions}

In this study, a cyclic loading test was carried out on RC subjected to different wet-dry cycles at different temperatures. The loading strain, plastic strain, and elastic strain of the specimens were compared and analyzed. Additionally, the damage variable was defined based on the elastic modulus and plastic strain. The main findings of this study are as follows:

(1) There existed primary pores and microcracks in the RC owing to the addition of hydrophobic rubber particles. The loading strain and plastic strain of the RC were obvious after the 1st loading cycle. As the number of loading cycles increased, the stress-strain curve became denser and the RC exhibited good elasticity.

(2) As the number of wet-dry cycles increased, the average plastic strain in the 10th-60th increased while the average elastic strain declined. Compared with the RC specimens without soaking, the average plastic strain in the 0th-60th loading cycle of the specimens, which were subjected to $7,14,21$, and 28 wet-dry cycles at $20^{\circ} \mathrm{C}$, increased by $31.82 \%, 40.91 \%$, $77.27 \%$, and $254.55 \%$, respectively.

(3) The elastic modulus of RC increased logarithmically with the number of wet-dry cycles. The total damage variable gradually increased, which indicates that the deterioration of $\mathrm{RC}$ is a continuing process induced by the wet-dry cycles. The damage variable of the elastic modulus was maximum during the 0 th-7th wet-dry cycles, that is, $16.27 \%$ at $20^{\circ} \mathrm{C}$ and $17.01 \%$ at $60^{\circ} \mathrm{C}$, respectively.

(4) The comparison of the damage variable, which was defined based on the elastic modulus and plastic strain, revealed that the coupled corrosion of the hygrothermal environment and cyclic loading made the deterioration of durability performance easier, and fatigue damage accumulated faster.

\section{Data Availability}

The datasets generated and analyzed during the current study are available from the corresponding author upon reasonable request.

\section{Conflicts of Interest}

The authors declare that there are no conflicts of interest regarding the publication of this paper.

\section{Acknowledgments}

This work was supported by China Postdoctoral Science Foundation (2020M681974), Natural Science Foundation of Anhui Province (KJ2020A0297), and Anhui University of Science and Technology (2020CX1004). Thanks are due to the State Key Laboratory of Mining Response and Disaster Prevention and Control in Deep Coal Mines, Engineering Research Center of Underground Mine Construction, for providing the experiment conditions.

\section{References}

[1] J. Xu, Z. Yao, G. Yang, and Q. Han, "Research on crumb rubber concrete: From a multi-scale review," Construction and Building Materials, vol. 232, Article ID 117282, 2020.

[2] X. Chen, Z. Liu, S. Guo, Y. Huang, and W. Xu, "Experimental study on fatigue properties of normal and rubberized selfcompacting concrete under bending," Construction and Building Materials, vol. 205, pp. 10-20, 2019. 
[3] F. Liu, L.-y. Meng, G.-F. Ning, and L.-J. Li, "Fatigue performance of rubber-modified recycled aggregate concrete (RRAC) for pavement," Construction and Building Materials, vol. 95, pp. 207-217, 2015.

[4] Y.-F. Wu, S. M. S. Kazmi, M. J. Munir, Y. Zhou, and F. Xing, "Effect of compression casting method on the compressive strength, elastic modulus and microstructure of rubber concrete," Journal of Cleaner Production, vol. 264, Article ID 121746, 2020.

[5] Y. C. Zhang and L. L. Gao, "Mechanical performance test of rubber-powder modified concrete," E3S Web of Conferences, vol. 38, Article ID 03006, 2018.

[6] O. Youssf, M. A. Elgawady, J. E. Mills, and X. Ma, "An experimental investigation of crumb rubber concrete confined by fibre reinforced polymer tubes," Construction and Building Materials, vol. 53, pp. 522-532, 2014.

[7] G. Xue, X. Zhang, and M. Cao, “Tests for damping energydissipation performance of rubber concrete considering temperature effect," Journal of Vibration and Shock, vol. 39, no. 19 , pp. $94-100,2020$.

[8] C. M. Copetti, P. M. Borges, J. Z. Squiavon, S. R. da Silva, and J. J. de Oliveira Andrade, "Evaluation of tire rubber surface pre-treatment and silica fume on physical-mechanical behavior and microstructural properties of concrete," Journal of Cleaner Production, vol. 256, Article ID 120670, 2020.

[9] E. Eltayeb, X. Ma, Y. Zhuge, O. Youssf, and J. E. Mills, "Influence of rubber particles on the properties of foam concrete," Journal of Building Engineering, vol. 30, Article ID 101217, 2020.

[10] K. A. Stallings, S. A. Durham, and M. G. Chorzepa, "Effect of cement content and recycled rubber particle size on the performance of rubber-modified concrete," International Journal of Sustainable Engineering, vol. 12, no. 3, pp. 189-200, 2019.

[11] S. Guo, Q. Dai, R. Si, X. Sun, and C. Lu, "Evaluation of properties and performance of rubber-modified concrete for recycling of waste scrap tire," Journal of Cleaner Production, vol. 148, pp. 681-689, 2017.

[12] B. S. Thomas, R. C. Gupta, P. Kalla, and L. Cseteneyi, "Strength, abrasion and permeation characteristics of cement concrete containing discarded rubber fine aggregates," Construction and Building Materials, vol. 59, pp. 204-212, 2014.

[13] W. Bai and J. Lv, "Experimental on damping capacity of rubber lightweight aggregate concrete," Journal of Chang'an University (Natural Science Edition), vol. 38, no. 3, pp. 27-33, 2018.

[14] T. Gupta, S. Chaudhary, and R. K. Sharma, "Mechanical and durability properties of waste rubber fiber concrete with and without silica fume," Journal of Cleaner Production, vol. 112, pp. 702-711, 2016.

[15] T. Gupta, A. Tiwari, S. Siddique, R. K. Sharma, and S. Chaudhary, "Response assessment under dynamic loading and microstructural investigations of rubberized concrete," Journal of Materials in Civil Engineering, vol. 29, no. 8, Article ID 04017062, 2017.

[16] R. Yang, Y. Xu, and Q. Zheng, "Fatigue and damage evolution characteristics of rubber cement mortar under graded constant load cyclic compression," Journal of Building Materials, vol. 7, pp. 1-12, 2020.

[17] Y. Zhang and Z. Zhao, "Internal stress development and fatigue performance of normal and crumb rubber concrete," Journal of Materials in Civil Engineering, vol. 27, 2015.

[18] J. Pang, Y. Chen, and X. Huang, "Effect of high stress equalamplitude cyclic loading on mechanical and deformation properties of rubberized concrete," Journal of Yangtze River Scientific Research Institute, vol. 37, no. 10, pp. 142-148, 2020.

[19] D. Y. Jiang, W. H. Liu, and J. Chen, "Fatigue performance of ordinary concrete subjected to stepwise discontinuous cyclic loading," Journal of Southeast University (Natural Science Edition), vol. 49, no. 4, pp. 631-637, 2019.

[20] J. Lv, T. Zhou, Q. Du, and K. Li, "Experimental and analytical study on uniaxial compressive fatigue behavior of self-compacting rubber lightweight aggregate concrete," Construction and Building Materials, vol. 237, Article ID 117623, 2020.

[21] R. Pacheco-Torres, E. Cerro-Prada, F. Escolano, and F. Varela, "Fatigue performance of waste rubber concrete for rigid road pavements," Construction and Building Materials, vol. 176, pp. 539-548, 2018.

[22] C. Hu, H. Zeng, and Y. Que, "Characteristics of concrete pavement temperature field and temperature stress in hot and humid areas," Journal of Fuzhou University (Natural Science Edition), vol. 39, no. 5, pp. 727-737, 2011.

[23] A. Abouhouraira, A. Ouali, O. Elhammoumi, L. Kassoumi, and A. Fekri, "Effect of accelerated ageing by cyclic variations of temperature and humidity on shrinkage of concretes," Materials Today, vol. 31, 2020.

[24] A. Mateos, J. Harvey, J. Bolander, R. Wu, J. Paniagua, and F. Paniagua, "Structural response of concrete pavement slabs under hygrothermal actions," Construction and Building Materials, vol. 243, Article ID 118261, 2020.

[25] S. A. Morshed, T. J. Young, W. M. Chirdon, Q. Zhang, and J. Tatar, "Durability of wet lay-up FRP bonded to concrete with nanomodified epoxy adhesives," The Journal of Adhesion, vol. 96, no. 13, pp. 1141-1166, 2020.

[26] S. A. Morshed, A. Sinha, Q. Zhang, and J. Tatar, "Hygrothermal conditioning of wet-layup CFRP-concrete adhesive joints modified with silane coupling agent and core-shell rubber nanoparticles," Construction and Building Materials, vol. 227, Article ID 116531, 2019.

[27] C. Tuakta and O. Büyüköztürk, "Deterioration of FRP/concrete bond system under variable moisture conditions quantified by fracture mechanics," Composites Part B: Engineering, vol. 42, no. 2, pp. 145-154, 2011.

[28] Y. Tang, H. Su, and H. Zhang, "Cohesive strength and micro failure mechanism of high geothermal diversion tunnel shotcrete surrounding rock," Water Resources Research, vol. 33, no. 4, pp. 127-129, 2015.

[29] E. I. Egba, M. Ismail, and N. Bakhary, “Temperature response in hardened concrete subjected to tropical rainforest environment," Engineering, Technology \& Applied Science Research, vol. 7, no. 3, pp. 1623-1628, 2017.

[30] S. N. Shoukry, G. W. William, B. Downie, and M. Y. Riad, "Effect of moisture and temperature on the mechanical properties of concrete," Construction and Building Materials, vol. 25, no. 2, pp. 688-696, 2011.

[31] M. Qin, N. Liang, and Z. Lu, "Fatigue property analysis of asphalt mixture in water-temperature action," Journal of Central South University, vol. 42, no. 4, pp. 1126-1132, 2011.

[32] H. Xin, J. Pang, G. Liu, and C. Yu, "The influence of equal amplitude high stress repeated loading on the mechanical and deformation characteristics of rubber concrete," Construction and Building Materials, vol. 266, Article ID 121135, 2021.

[33] A. Gholampour, T. Ozbakkaloglu, and R. Hassanli, "Behavior of rubberized concrete under active confinement," Construction and Building Materials, vol. 138, pp. 372-382, 2017.

[34] G. Hu, Q. Zhao, and Y. He, "Elastic modulus's evolution law of plangiogranite under cyclic loading," Journal of Engineering Geology, vol. 24, no. 5, pp. 881-890, 2016. 
[35] M. N. Noorsuhada, "An overview on fatigue damage assessment of reinforced concrete structures with the aid of acoustic emission technique," Construction and Building Materials, vol. 112, pp. 424-439, 2016.

[36] M. Liu, J. Lu, P. Ming, and J. Liu, "Effect of fatigue load on damage and fracture properties of rubber concrete," Acta Materiae Compositae Sinica, vol. 38, pp. 1594-1603, 2020.

[37] D. Jiang, Y. Cui, and J. Fan, "Experimental study of mechanical characteristics of salt rock under discon- tinuous cyclic loading," Rock and Soil Mechanics, vol. 38, no. 5, pp. 1327-1334, 2017.

[38] X. Liu, D. Li, Z. Wang, and L. Zhang, "The effect of dry-wet cycles with acidic wetting fluid on strength deterioration of shaly sandstone," Chinese Journal of Rock Mechanics and Engineering, vol. 35, pp. 1543-1554, 2016.

[39] Q. Ma, P. Yu, and P. Yuan, "Experimental study on creep properties of deep siltstone under cyclic wetting and drying," Chinese Journal of Rock Mechanics and Engineering, vol. 37, pp. 593-600, 2018. 